\title{
Analysis on the Relation Between Stake Size Effect and Fehr-Schmidt's Parameters
}

\begin{abstract}
Jiaming Fan
University of St Andrews

jf251@st-andrews.ac.uk

Corresponding author. Email: gaoming@cas-harbour.org

ABSTRACT

Stake Size Effect demonstrates the phenomenon that in Ultimatum Game, individuals have much lower rejection rates when facing the same proportion of offers but with higher stake sizes. This article relates the Stake Size Effect with the Fehr-Schmidt model, which is one of the most important models in explaining the role of fairness in bargaining games. The author was interested in finding a simple relationship between stake size and parameters of inequity in the Fehr-Schmidt model. The model was first built based on data collected in Andersen et al.'s experiment by using linear regression technique and then checked with other empirical data[1]. Although the result shows a large difference between experiments as the effectiveness of the built model varies in a wide range, a rough trend between the change of log stake size and the change of $\log$ parameters can be seen.
\end{abstract}

Keywords: Ultimatum Game, Game Theory, Fehr-Schmidt model, stake size, Inequity aversion

\section{INTRODUCTION}

In neoclassical economics, individuals are always assumed to be rational and self-interested. However, with the development of experimental economics, which has been developed as a method of analyzing the specific game in game theory, there is increasingly more empirical evidence weakening the rational-person assumption. This evidence is more obvious in game theory analysis. In many lab experiments of game theories, subjects diverge from the traditional game theory predictions.

Social preference on equity is considered an important factor affecting subjects' behaviors in those games. The early game theory experiment conducted demonstrated that, in the Ultimatum Game, people do care about fairness in real life[9]. And there are theories One of the most famous models for inequity aversion is the Fehr-Schmidt model (1999).

A previous study has proven that stakes sizes matter in Ultimatum Games, which means individuals' social preference on equity or fairness is influenced by the amount of money in the Ultimatum Game[1]. In their report, a logit regression linear model was built for four different stakes offered in the designed experiments.
However, the model did not build a direct relationship between inequity parameters and stake size.

This article tries to build a simple model for stake size and two parameters describing social preference on fairness in Fehr-Schmidt mode based on Andersen and his colleagues' results and make reasonable conjectures on factors causing the stake size effect in Ultimatum Game. The relationship attempted to build may provide a clearer explanation for the revealed sociopsychological effect or bias that individuals' social preference on fairness and the stake size effect.

\section{FEHR-SCHMIDT MODEL}

Fehr-Schmidt model, firstly introduced in 1999 by E. Fehr and K. M. Schmidt in "A Theory of Fairness, Competition, and Cooperation", Quarterly Journal of Economics. The Fehr-Schmidt model asserted that individuals have certain social preferences from a reference point called Fehr-Schmidt inequity-averse preferences in competitive games. Fehr-Schmidt inequity-averse preferences indicated that besides the amount earned, people have both disadvantageous inequity (negative dependence on fewer gains compared to others) and advantageous inequity (negative dependence on more gains compared to others). 
Individual $i$ has Fehr-Schmidt inequity-averse preferences at $\mathrm{x}$ if

$$
U_{i}\left(x_{i}, x_{-i}\right)=x_{i}-\frac{\alpha_{i}}{n-1} \cdot \sum_{i \neq i} \max \left\{x_{j}-x_{i}, 0\right\}-\frac{\beta_{i}}{n-1} \sum_{i \neq i} \max \left\{x_{i}-x_{j}, 0\right\}
$$

Where

$$
\text { a } \mathrm{i} \geqslant 0 \text { is a parameter capturing }
$$
disadvantageous inequity (or parameter of envy)

- $\beta \mathrm{i} \in[0,1)$ is a parameter capturing advantageous inequity (or parameter of guilty)

This model assumed that the utility function is linear to keep the marginal rate of substitution between gains and inequity aversion constant. And as the coefficients of $\alpha$ and $\beta$ are assumed to be larger than zero, this property makes sure that there is no pure selfish or altruistic person in the Fehr-Schmidt model. The larger the value of $\alpha$ is, the more the individual dislikes being treated unfairly in a bad way. And the larger value of $\beta$ is, the more the individual dislikes to treat others in a bad way.

There are several empirical estimates for $\alpha$ and $\beta$. Fehr and Schmidt have made $\alpha$ and $\beta$ estimates of $(0.85$, 0.315) [8]. Many subsequent pieces of research also aimed at estimating $\alpha$ and $\beta$. Eckel and Gintis have shown that $\alpha$ and $\beta$ vary from a range of ( 0.31 to 1.89$)$ and (0.34 to 0.80$)$ in the aggregate level [7]. More precise estimates are made by Goeree and Holt. A 0.84 $\alpha$ value has been estimated in Goeree and Holt's experiment, however, they found a significant difference in $\beta$ value between proposers $(0.66)$ and responders (0.12) [9]. Diaz et al's experiment yields much lower $\alpha$ and $\beta$ estimates of $(0.20,0.06)$ [6]. Due to different experimental designs and external factors, no real consensus about the Fehr-Schmidt model's values of parameters has been reached.

\section{REVIEW ON ANDERSEN ET AL.,'S EXPERIMENT}

Andersen and his colleagues conducted the Ultimatum Game experiments in Indian rural areas with four different stake sizes of 20,200, 2,000, and 20,000 rupees.
The proposers were instructed to maximize the earnings in the experiment to elicit a lower offer while responders were instructed to follow the standard rule for ultimatum games. And each subject was only designed to play the game once so that no difference in experimental results could be attributed to learning.

The average share offered by proposers declines as stake size increases. For 20 rupees, an average $24 \%$ of the stake was offered. For a 200-rupee stake, about $17 \%$ share was offered. An even more lower share was offered with two higher stakes, as shown in figure 1.

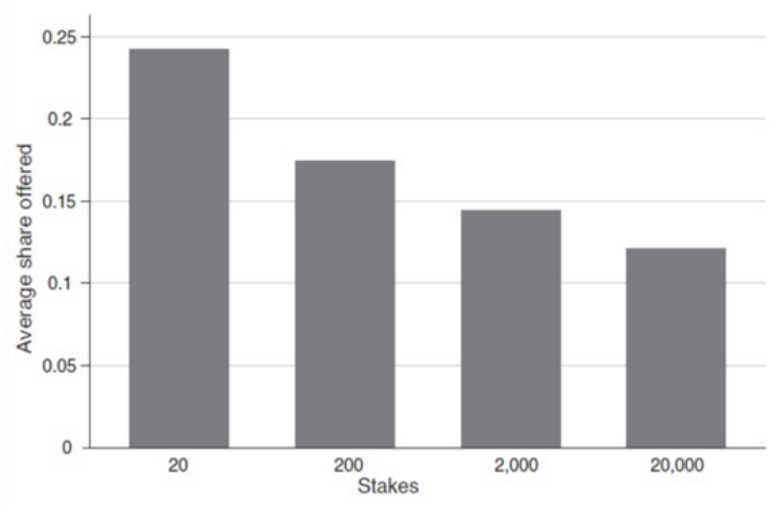

Figure 1. Average share offered by proposers with four different stakes

The stake size also influences responders' behavior. The results indicated a negative relationship between rejection rates and stake sizes. The overall rejection rates were 46\% (20 Rp), 36\%(200 Rp), 20\% (2,000 Rp), $0 \%$ (20,000 Rp), respectively.

In the logit regression results, although stake size 2 (200 rupees) has a positive parameter $(+0.152)$, the parameters of stake size 3 (2,000 rupees) and $4(20,000$ rupees) showed negative values $(-0.640$ and -2.874$)$. The parameters for stake sizes revealed a declining trend. Hence, it could be concluded that proportionally equivalent offers with higher stakes are less likely to be rejected. This effect is called the "stake size effect".

Table 1. A Part of statistical outputs of the fitted model.

\begin{tabular}{|c|c|c|c|c|}
\hline Coefficients: & & & \\
\hline & Estimate & Std. Error & t value & $\operatorname{Pr}(>|t|)$ \\
\hline (Intercept) & -0.28674 & 0.13025 & -2.202 & 0.1586 \\
\hline $\log ($ Stake Size $)$ & -0.17145 & 0.01876 & -9.141 & 0.0118 \\
\hline
\end{tabular}


Since the responders were told to maximize their earnings, the value of $\beta$ has no significant difference with zero in this experiment. So we will focus on calculating for estimating the value of $\alpha$.

\section{RE-ANALYSING ANDERSEN ET AL.,'S DATA}

\subsection{Estimating $\alpha$ by using the results of Andersen et al's research}

This article will mainly focus on the responders' social preferences because the accepted offers are the only revealed social preferences. For simplifying the data, the aggregate level will be calculated in the following paragraphs.
In order to estimate the values for $\alpha$, the average accepted amount was calculated, as shown in table 2.

Because the responders chose to accept the offers rather than reject them, the utilities must be no less than zero. Hence, we have $\mathrm{Xi}-(\mathrm{Xj}-\mathrm{Xi}) * a \geqslant 0$ (two-player ultimatum game so $(n-1=1)$. By calculation, ranges of $a$ for four stake sizes are $a \leqslant 0.48(20), \alpha \leqslant 0.27$ (200), $\alpha \leqslant 0.21(2,000)$ and $a \leqslant 0.14(20,000)$, respectively.

From the estimates for a above, some evidence of the "stake size effect" can be seen. The maximum value of a decreases as the stake size rises. And by recalling the real-life reflection of the a parameter, it is deduced that an increase in stake size leads to a lower aversion to be treated disadvantageously.

Table 2. Average accepted amount of 4 stake sizes

\begin{tabular}{|c|c|c|}
\hline Stake Size & $\begin{array}{c}\text { Average accepted amount }(0.1 \\
\text { significant })\end{array}$ & $\begin{array}{c}\text { Average accepted amount rate }(0.1 \% \\
\text { significant })\end{array}$ \\
\hline 20 & 4.9 & $24.5 \%$ \\
\hline 200 & 35.1 & $17.6 \%$ \\
\hline 2,000 & 293.7 & $14.7 \%$ \\
\hline 20,000 & 2130.4 & $10.7 \%$ \\
\hline
\end{tabular}

\subsection{Building a fitted regression model of} "stake size effect"

By establishing a linear regression model with log transformation, a fitted linear relationship between log maximum $\alpha$ value and log stake size is found.

It reveals that $\log ($ maximum $\alpha$ value $)=-0.28674-$ $0.17145^{*} \log ($ Stake Size $)$ and we transform it back. Size)

-> $\triangle \log (\operatorname{maximum} \alpha$ value $)=-0.17145^{*} \triangle \log ($ Stake

This means that one unit increase of log stake size would result in a 0.17145 unit decrease in log maximum $\alpha$ value in the ultimatum game.

\subsection{Evaluating the effectiveness of the established model}

From the outputs of our fitted model, some evidence is revealed as the p-value does not reject the relationship between $\log$ maximum $\alpha$ value and $\log$ stake size at $5 \%$ confidence interval. But it is not enough for $1 \%$ confidence interval.

\subsection{Evaluating the effectiveness by checking empirical results into the fitted model}

Now using other empirical results to check its effectiveness. Heinz, Juranek \& Rau (2012) has $\triangle \log ($ maximum $\alpha$ value $)=-0.242189816$, and a $-0.1188400841-0.17145 * \triangle \log ($ Stake Size $)$ value.

In Cameron, L.a.'s (1999) experiment, two games involving changes of stake sizes are conducted and there are two rounds in the game with the lower stake in the first round and higher stake in the second round. In the first game, 5,000 rupiahs are distributed in the first round and 40,000 rupiahs are distributed in the second round. The $\triangle \log$ (maximum $\alpha$ value) equals to -0.63670 while $-0.17145^{*} \triangle \log ($ Stake Size $)$ equals to -0.35652 . In the first game, 5,000 rupiahs are distributed in the first round and 200,000 rupiahs are distributed in the second round. The $\triangle \log ($ maximum $\alpha$ value $)$ equals to 0.6446388464 while $-0.17145^{*} \triangle \log ($ Stake Size $)$ equals to -0.6324583824 .

It is worth noticing that the stake size effect does exist in many experiments, however, the model should have a lower (larger in absolute value) coefficient. 0.17145 is lower than the empirical values. A coefficient around -0.4 to -0.3 would fit the two experiments above.

\section{DISCUSSION}

The purpose of this article is to build a simple and direct relationship between the parameter of the FehrSchmidt model based on the very foundation study of " thestake size effect", Andersen et al's article. A clear 
linear relationship has been drawn after log transformation[1]. Moreover, the linear model built here showed not bad performance when facing the statistical test.

However, more limitations had been revealed in the study. The data set used for building models has a very small sample size since our data is all based on the experiments of Andersen et al,. Although Andersen et al's study included four stake sizes, which is relatively high among all studies on stake size effect based on Ultimatum Game, it is too small for building a regression model. If the sample size increases, the way of transformation used for approaching linear relation might change.

The reason for the small sample size may due to the difficulty of designing a practicable experiment with many different stake sizes. Besides Andersen et al's experiment, few studies have a difference in stake size larger than 1000, and there are only several experiments have 100 times of stake size difference. The limited budget and moral problems could also be the problem of experimental designing and conducting. For improvements, we should continue experimenting on ultimatum games with the same assumptions and settings. Then, we use the acquired data to check our model or build a more precise model.

Moreover, the power stake size effect would also be a problem. A wide variety of studies have been conducted for measuring the power of the stake size effect. Some studies found an increase in stake size has a significant negative effect on offer rates, such as Carpenter et al.,[4] and Harrison \& El Mouden [11]. This stake size effect is also the assumption of the built model in this article. However, many researchers such as Carr \& Mellizo also found a negative stake effect[5]. It is even more confusing that some studies failed to find a significant relation between stake size and offer rate. Raihani et al., found stake size has very little effect on decision-making in the US [12].

Many factors are affecting the results of measuring the power of the stake size effect. One of the most important is the subject difference. Different subject groups may have different preferences on fairness. High-educated subjects may have very high $\alpha$ and $\beta$ values. And social morality and the initial wealth of subjects may also be attributed to the social preference difference [2].

\section{CONCLUSION}

In conclusion, the article showed a negative relationship between the change of responders' log average accepted amounts and the change of log stake size based on Andersen et al's research, and the increase in stake size leads to a smaller proportion decrease in . Although the t-test statistics looked good(which means the model built showed a solid linear relationship), the model had a bad performance with other empirical data. For eliminating the influence of other factors such as education levels and geographic distribution, more surveys with similar subjects and locations should be conducted in order to build a more precise model.

\section{REFERENCES}

[1] Andersen, S., Ertaç, S., Gneezy, U., Hoffman, M., \& List, J. A. (2011). Stakes matter in ultimatum games. American Economic Review, 101(7), 3427-3439.

https://doi.org/10.1257/aer.101.7.3427.

[2] Bellmare, C., Kröger, S., van Soest, A., 2007. Preferences, intentions, and expectations: a largescale experiment with a representative subject pool. IZA (Institute for Labor Economics) Working Paper No. 3022.

[3] Cameron, L.a. (1999). Raising the stakes in the ultimatum game: Experimental evidence from Indonesia. Economic Inquiry, 37(1), 47-59. https://doi.org/10.1111/j.14657295.1999.tb01415.x.

[4] Carpenter, J., Verhoogen, E., \& Burks, S. (2005). The effect of stakes in distribution experiments. Economics Letters, 86(3), 393-398. https://doi.org/10.1016/j.econlet.2004.08.007.

[5] Carr, M. D., \& Mellizo, P. (2017). The effect of endogenous endowments: Evidence from a miniultimatum game. Economics Bulletin, 37, 25522560 .

[6] Diaz, L., Houser, D., Ifcher, J., \& Zarghamee H. (2021). Estimating Social Preferences Using Stated Satisfaction: Novel Support for Inequity Aversion. IZA DP No. 14347. https://ftp.iza.org/dp14347.pdf

[7] Eckel, C., Gintis, H., 2010. Blaming the messenger: notes on the current state of experimental economics. J. Econ. Behav. Org. 73, 109-119. https://doi.org/10.1016/j.jebo.2009.03.026.

[8] Fehr, E., \& Schmidt, K. M. (1999). A theory of fairness, competition, and cooperation. The Quarterly Journal of Economics, 114(3), 817-868.

[9] Goeree, J., Holt, C.A., 2000. Asymmetric inequality aversion and noisy behavior in alternating-offer bargaining games. European Economic Review 44, 1079-1089.

[10] Güth, W., Schmittberger, R., \& Schwarze, B. (1982). An experimental analysis of ultimatum bargaining. Journal of Economic Behavior and 
Organization, 3(4), 367-388. https://doi.org/10.1016/0167-2681(82)90011-7.

[11] Harrison, F., \& El Mouden, C. (2011). Exploring the effects of working for endowments on behaviour in standard economic games. e27623
PLoS

ONE,

$6(11)$ https://doi.org/10.1371/journal.pone.0027623.

[12] Raihani, N. J., Mace, R., \& Lamba, S. (2013). The effect of $\$ 1, \$ 5$ and $\$ 10$ stakes in an online dictator game. PLoS ONE, 8(8), E73131. https://doi.org/10.1371/journal.pone.0073131. 